University of Nebraska - Lincoln

DigitalCommons@University of Nebraska - Lincoln

2011

Hydrogen and moisture-induced scale spallation: Cathodic descaling of a single crystal superalloy

James L. Smialek

NASA Glenn Research Center, james.I.smialek@nasa.gov

Follow this and additional works at: https://digitalcommons.unl.edu/nasapub

Part of the Physical Sciences and Mathematics Commons

Smialek, James L., "Hydrogen and moisture-induced scale spallation: Cathodic descaling of a single crystal superalloy" (2011). NASA Publications. 89.

https://digitalcommons.unl.edu/nasapub/89

This Article is brought to you for free and open access by the National Aeronautics and Space Administration at DigitalCommons@University of Nebraska - Lincoln. It has been accepted for inclusion in NASA Publications by an authorized administrator of DigitalCommons@University of Nebraska - Lincoln. 


\title{
Hydrogen and moisture-induced scale spallation: Cathodic descaling of a single crystal superalloy
}

\author{
James L. Smialek* \\ NASA Glenn Research Center, Cleveland, $\mathrm{OH} 44135$, United States
}

\section{A R T I C L E I N F O}

\section{Article history:}

Received 2 July 2010

Received in revised form

21 September 2010

Accepted 22 September 2010

Available online 29 September 2010

\section{Keywords:}

Superalloys

Alumina scales

Moisture

Hydrogen embrittlement

Sulfur segregation

\begin{abstract}
A B S T R A C T
Moisture-induced delayed spallation (MIDS) of protective alumina scales at room temperature is a well known phenomenon. One mechanism proposes that water and $\mathrm{Al}_{\text {alloy }}$ react, produce hydrogen at the scale-metal interface, and enable spallation. To test this mechanism, preoxidized samples of a single crystal superalloy, Rene'N5 + Y, were subjected to standard cathodic hydrogen charging treatments known to produce hydrogen embrittlement in bulk $\mathrm{Ni}$ and $\mathrm{Ni}_{3} \mathrm{Al}$ alloys. Cathodic hydrogen charging, at $<1 \mathrm{~mA}$ and an estimated $-0.45 \mathrm{~V} \mathrm{SCE}$, stripped the scales at the oxide-metal interface, resulting in an initial loss of $\sim 3 \mathrm{mg} / \mathrm{cm}^{2}$ and little additional change with time. This was supported by macro-photos and SEM of the spalled surface. On the other hand, anodic polarization at $<1 \mathrm{~mA}$ produced less, but steady, linear weight loss $\left(0.3 \mathrm{mg} / \mathrm{cm}^{2}\right)$, primarily by anodic dissolution of the metal. Hydrogen charging was thus shown to be detrimental to the alumina scale-metal bond, supporting the hydrogen factor in MIDS. These and other MIDS results show remarkable similarities to embrittlement of Ni subject to hydrogen charging at similar potentials and varying amounts of interfacial (grain boundary) sulfur segregation. The MIDS phenomenon is also discussed in terms of comparative static corrosion fatigue characteristics. It is not necessarily related to other diverse moisture effects occurring at high temperature.
\end{abstract}

Published by Elsevier Ltd.

\section{Introduction}

High temperature turbine materials rely on the formation of protective alumina scales for durable operation. Single crystal $\mathrm{Ni}$-based superalloy airfoils and aluminide $\mathrm{Ni}(\mathrm{Pt}) \mathrm{Al}$ or overlay $\mathrm{Ni}(\mathrm{Co}) \mathrm{Cr}$ AlY coatings all produce slow growing, $\alpha-\mathrm{Al}_{2} \mathrm{O}_{3}$ scales with varying degrees of adherence. These coatings may also be used as bond coatings beneath YSZ (yttria-stabilized zirconia) thermal barrier coatings (TBC). The integrity of the scale-alloy interface is key to long-term cyclic durability of $\mathrm{Al}_{2} \mathrm{O}_{3}$ protected and TBC coated alloys. For many years, the strength of this bond has been shown to be increased by reactive element (Y, Hf, Zr, La, etc.) doping (0.001-0.1 wt.\%) or decreased by trace levels of sulfur impurities (1-20 ppmw) that segregate to the interface. Pt is another effective dopant. However moisture in the ambient air is a secondary factor affecting failure of the scale or TBC, but well after cooldown [1]. This is especially true in the case of mature, damaged, or less adherent scales.

Thus, secondary, moisture-induced delayed spallation (MIDS) at room temperature has been of some interest since it was initially observed [2,3]. Experience in our laboratory has been summarized

\footnotetext{
* Corresponding author. Tel.: +1 216433 5500; fax: +1 2164335544 .

E-mail address: James.l.smialek@nasa.gov.
}

[1], along with critical experiments by numerous other investigations. Basically, an otherwise adherent $\alpha-\mathrm{Al}_{2} \mathrm{O}_{3}$ scale is observed to spall over a period of time after cool down, as affected by ambient or intentionally added moisture or water immersion. Moistureassisted crack growth in bulk alumina at room temperature has been pointed out as a possible mechanism in play at the scale-metal interface [4-6]. This is derived from a chemical reaction between water and alumina:

$\mathrm{Al}_{2} \mathrm{O}_{3}+3 \mathrm{H}_{2} \mathrm{O}_{\text {ambient }}=2 \mathrm{Al}(\mathrm{OH})_{3}$

Thus hydroxide is formed at the crack tip with a consequent loss of interfacial strength. A similar alternative mechanism has been proposed [7], whereby water reacts with aluminum in the alloy at room temperature, again forming hydroxide, but now releasing hydrogen in the vicinity of the interface:

$\mathrm{Al}_{\text {alloy }}+3 \mathrm{H}_{2} \mathrm{O}_{\text {ambient }}=2 \mathrm{Al}(\mathrm{OH})_{3}+3 \mathrm{H}_{\text {ads }}$

Using a thermodynamic database, the free energy of reaction 1 was calculated to be $0.17 \mathrm{~kJ} / \mathrm{mole}_{2} \mathrm{O}$ at room $298 \mathrm{~K}$, while that of reaction (2) was $290 \mathrm{~kJ} /$ mole $\mathrm{H}_{2} \mathrm{O}$ (using unit activity of $\mathrm{Al}$ for the sake of simplicity). On this basis, reaction (2) may be expected to predominate by a factor of $1.7 \times 10^{3}$, although both may contribute to interface weakening via separate mechanisms.

A number of MIDS characteristics have been pointed out to have compelling analogies with other systems exhibiting room 
temperature, moisture-induced hydrogen embrittlement of interfaces in metals: multiaxial tension, delayed, intermittent intergranular failure, and synergistic effects with interfacial sulfur. A recent position paper further describes the proposed mechanism of moisture-induced hydrogen embrittlement of the alumina scale interface [8]. Here a logic tree is constructed from the top down to highlight a number of salient and supporting points:

- Hydrogen gas has been measured as a reaction product between water and $\mathrm{Al}$ powder.

- Ab initio studies report as much as a $90 \%$ decrease in pure Co-pure $\mathrm{Al}_{2} \mathrm{O}_{3}$ interfacial strength with increased $\mathrm{H}$.

- Moist air or $\mathrm{Ar}, \mathrm{H}_{2}$ gas, and electrochemical $\mathrm{H}$-charging all reduce the ductility of $\mathrm{Ni}_{3} \mathrm{Al}, \mathrm{Fe}_{3} \mathrm{Al}$, and $\mathrm{FeAl}$ aluminides and Ni-alloy 718 compared to vacuum or dry $\mathrm{O}_{2}$ test environments.

- Cathodic H-charging of pure Ni increases intergranular embrittlement, in combination with segregated sulfur levels, from just $2 \%$ of the fracture area (for low $\mathrm{S}$, low $\mathrm{H}$ ) up to $95 \%$ (for high $\mathrm{S}$, high $\mathrm{H}$ ).

- Exposure to moisture produced bubbles under native alumina films on $\mathrm{Al}$.

- $\mathrm{H}$ and D-implantation produced bubbles and blisters under anodic films on $\mathrm{Al}$, while He-implantation did not.

- $\mathrm{H}$ was detected at the scale-metal interface of anodized Al.

Thus a framework is established for arguing that moisture can react with $\mathrm{Al}$ in the alloy at room temperature to produce hydrogen at regions of partial spallation or through-cracks in the scale. Under the action of large tensile oxide/alloy CTE mismatch stresses, hydrogen can diffuse in the metal along the interface and produce weakening. Conversely, the scale is subject to a residual compressive stress and corresponding levels of strain energy. The interfacial toughness may be compromised by sulfur accumulating from oxidative surface recession or by segregation from the bulk. A negative synergistic effect with hydrogen is demonstrated when spalling occurs at a sulfur level insufficient to cause spallation independently. The process is controlled in part by hydrogen diffusion and will exhibit an intermittent behavior as successive scale segments are compromised, spall, and expose new reaction sites.

Our previous work, among those of others, has described the behavior of a second generation single crystal superalloy, GE Rene' $5^{\mathrm{TM}}$, in regards to its excellent cyclic oxidation behavior and sensitivity to subsequent moisture exposures [6,9]. In general, good adhesion behavior is demonstrated by Y-doped versions, and improvements in moisture-assisted spallation were conferred by hydrogen annealing. Except for the undoped alloy, the normal beneficial hydrogen annealing effect, that of reducing bulk sulfur to $\leq 0.1$ ppmw, did not occur here, and possible effects of decarburization were discussed.

The purpose of the present study, then, is to demonstrate the negative effect of hydrogen on scale adhesion for Rene'N5. To isolate the detrimental effect of hydrogen from moisture, the same approach was adopted as that producing embrittlement in Ni alloys, i.e., cathodic hydrogen charging. Basically a small negative polarization in $\mathrm{H}_{2} \mathrm{SO}_{4}$ electrolytes can be used to accumulate hydrogen in metals. Here we used Rene'N5 samples oxidized in the earlier study as electrodes, under the expectation that an excess of hydrogen would accentuate interfacial spalling for damaged, highly stressed mature scales. The results, initially summarized in Ref. [7], are described in detail here. Polarization behavior, surface microstructure, and weight loss were all characterized. By calibrating the working polarization against standard electrodes, the spallation behavior was more quantitatively compared to the study of cathodic embrittlement of $\mathrm{Ni}$.

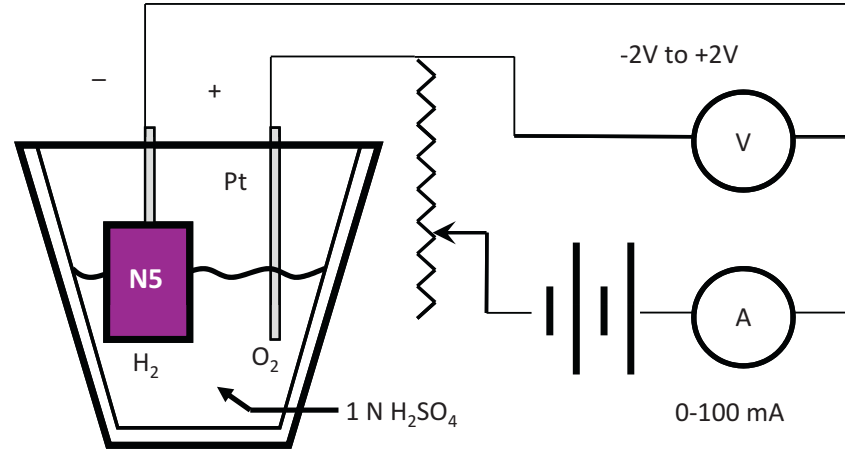

Fig. 1. Schematic of cell for electrolytic hydrogen charging treatments of preoxidized Rene'N5 in $1 \mathrm{~N} \mathrm{H}_{2} \mathrm{SO}_{4}$.

\section{Experimental}

Rene'N5 samples in the form of $1 \mathrm{~mm} \times 12.5 \mathrm{~mm} \times 25.4 \mathrm{~mm}$ coupons, were preoxidized for 10001 -h cycles at $1150^{\circ} \mathrm{C}$. These were selected from a series of compositions with varying $\mathrm{Y}$ content $(\sim 0-100 \mathrm{ppmw})$. From the literature, electrolytic hydrogen charging is often accomplished in $\mathrm{S}$, $\mathrm{P}$, or As poisoned $\mathrm{H}_{2} \mathrm{SO}_{4}$, at currents $\leq 150 \mathrm{~mA} / \mathrm{cm}^{2}$ and potentials $\leq-2 \mathrm{~V}$ ( $\left.\mathrm{vs} \mathrm{Ag} / \mathrm{AgCl}\right)$ [10-12] Our simple charging cell is shown schematically in Fig. 1, using only a 0.020 in. Pt wire counter-electrode without a reference electrode. The working electrode consisted of the N5 coupons suspended from a Pt wire, submerged about halfway into the $100 \mathrm{~mL}$ solution. The bottom edge of the coupon was sanded to insure a conductive path to the oxide-metal interface, providing a minimum exposed surface area of $\sim 0.125 \mathrm{~cm}^{2}$. A constant voltage power supply was used to apply a potential, while cell current was measured using a precision potentiometer across a low resistance load of $1 \Omega$. Duplicate N5 $+Y$ samples were exposed to a constant positive or negative potential and monitored for response by current, weight change, surface macro and microstructure. The potentials were chosen based on the general response of a bare control sample. Generally the low current knee of the current-voltage response curve was used to initiate charge transfer with minimal electrolysis and gas formation. Scanning electron microscopy (SEM) with energy dispersive spectroscopy (EDS) was performed on both cathodically (-) and anodically $(+)$ treated oxidized samples and on a bare undoped sample after an anodic and cathodic exposure. Secondary (SE) and backscatter (BSE) electron imaging were used to accentuate morphological details and chemical contrast, respectively.

\section{Results and discussion}

The Rene'N5 sample identification, preoxidation, immersion, and electrochemical treatment data are summarized in Table 1 . The $\mathrm{H}_{2}$ condition refers to hydrogen annealing in $5 \% \mathrm{H}_{2} / \mathrm{Ar}$ at $1250{ }^{\circ} \mathrm{C}$ for $100 \mathrm{~h}$. (Any hydrogen pickup during the anneal is generally assumed to disperse upon slow furnace cooling because of the high diffusivity of hydrogen). The Y and $\mathrm{S}$ content was determined by glow discharge mass spectroscopy (GDMS). The net weight change is after 10001 -h oxidation cycles at $1150{ }^{\circ} \mathrm{C}\left(\Delta W_{1000 \mathrm{~h}}\right)$, and $\mathrm{H}_{2} \mathrm{O}$ $\left(\Delta W_{\mathrm{H}_{2} \mathrm{O}}\right)$ weight is the additional spallation due to water immersion. Current and weight losses are given for $1 \mathrm{~h}$ charging in $1 \mathrm{~N}$ $\mathrm{H}_{2} \mathrm{SO}_{4}$ at the applied potentials shown.

\subsection{Electrochemical response}

Fig. 2 illustrates that a rapid decay in current occurs for both cathodic $(-2.0 \mathrm{~V})$ and anodic $(+1.3 \mathrm{~V})$ continuous polarizations, with the significance of these potentials described later. Also, the 
Table 1

Samples, conditions, and weight changes for oxidation and electrolytic treatments.

\begin{tabular}{|c|c|c|c|c|c|c|c|c|}
\hline Sample & Condition & Y ppmw & S ppmw & $\Delta W_{1000 \mathrm{~h}} \mathrm{mg} / \mathrm{cm}^{2}$ & $\Delta W_{\mathrm{H}_{2} \mathrm{O}} \mathrm{mg} / \mathrm{cm}^{2}$ & Volts & $\mathrm{mA}$ & $\Delta W_{1} \mathrm{mg} / \mathrm{cm}^{2}$ \\
\hline $67-1$ & $\mathrm{H} 2$ & 80 & 5.5 & 0.961 & -0.068 & $\begin{array}{r}0.0 \\
-2.0\end{array}$ & $\begin{array}{r}0.00 \\
-0.37\end{array}$ & $\begin{array}{l}-0.041 \\
-2.730\end{array}$ \\
\hline $67-2$ & A.R. & 80 & 4.9 & -1.048 & -0.122 & -2.0 & -0.43 & -1.315 \\
\hline $48-1$ & $\mathrm{H} 2$ & 20 & 7.0 & 0.638 & -0.107 & 1.3 & 0.70 & $-0.258^{*}$ \\
\hline $48-2$ & A.R. & 20 & 5.2 & -0.972 & -0.415 & 2.0 & 112.0 & $-5.462^{* *}$ \\
\hline N5-0 & A.R. & 0.3 & 2.6 & N.A. & N.A. & $\begin{array}{r}1.8 \\
-3.0\end{array}$ & $\begin{array}{r}3.1 \\
-95\end{array}$ & $\begin{array}{l}-3.983 \\
-0.541\end{array}$ \\
\hline
\end{tabular}

${ }^{*}$ A final treatment of 2 min at $-2.0 \mathrm{~V}$ resulted in a summed weight change of -0.347 .

** A final ultrasonic treatment resulted in a summed weight change of -8.317 .

steady state currents are seen to approach small values, i.e., $\leq 1 \mathrm{~mA}$, in both cases. Current density could be estimated from the exposed surface area $\left(0.125 \mathrm{~cm}^{2}\right)$ of the sanded edge. However metal area exposed by spalling would introduce a uncertainty in such an estimated $i / A$ value. Separate, intermittent polarization exposures were employed for various inspections (weight change and macrographs). These are summarized by the filled data points for current normalized to their initial values at $t=0.2 \mathrm{~min}$ for cathodic, Fig. 3a, and anodic, Fig. 3b, experiments. In all cases, the relative current after an interrupted exposure was similar to those of the continuous exposures. Also, current decay is always the most severe in the initial $2 \mathrm{~min}$ and then approaches a more steady state level. The current after about $2 \mathrm{~min}$ is then selected to provide a fairly reproducible characteristic output for any applied potential. It is believed that the decay response is a simple chemical polarization resulting from compositional gradients developing in the unstirred electrolyte as ions and radicals build up in the liquid diffusion layer.

Accordingly, the current after a standard 2 min decay period for either fixed or stepped $(0.1-0.2 \mathrm{~V})$ applied potential inputs was employed to develop the current/applied potential characteristic response (i.e., voltammogram). Fig. 4 summarizes this response for coupons pre-oxidized for 10001 -h cycles at $1150^{\circ} \mathrm{C}$. Samples $67-$ 1 and 48-1 had been prepared by hydrogen annealing $\left(5 \% \mathrm{H}_{2} / \mathrm{Ar}\right.$ at $1250^{\circ} \mathrm{C}$ for $100 \mathrm{~h}$ ); whereas samples $67-2$ and $48-2$ had been oxidized in the as-received condition. It is immediately clear that rapid current increases resulted for cathodic polarization at $-2.0 \mathrm{~V}$ or lower or for anodic polarization at $+1.3 \mathrm{~V}$ or higher. These characteristic 'knees' in the response curve, then, were selected as our operational parameters for extended cathodic or anodic treatments. Severe bubbling at the working electrodes and excessive (up to $\sim 100 \mathrm{~mA}$ ) currents were noted above $+1.3 \mathrm{~V}$ or below $-2.0 \mathrm{~V}$. This indicated substantial overvoltages for the generation of $\mathrm{O}_{2}$

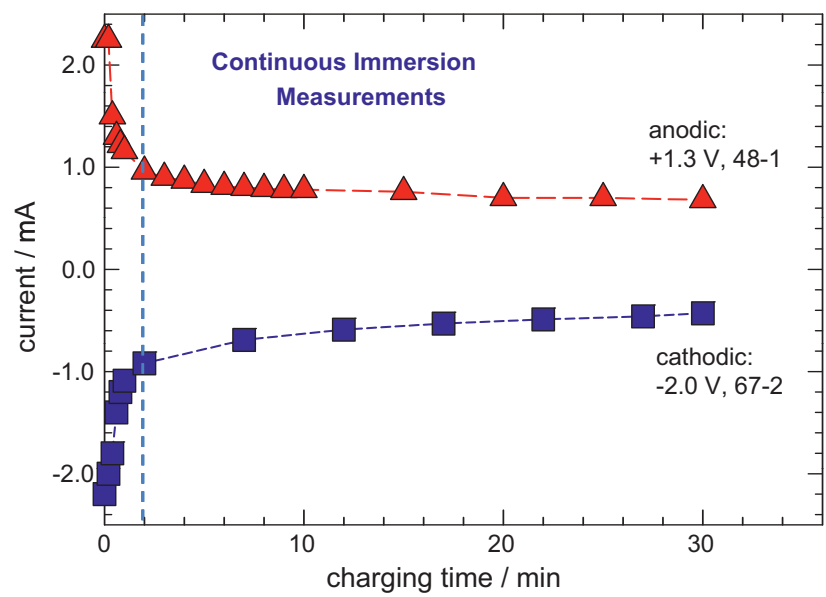

Fig. 2. Current decay for continuous anodic and cathodic polarization of preoxidized Rene'N5. or $\mathrm{H}_{2}$ gas, respectively, at the working sample electrode. Between these extremes the currents were much smaller $(<2.5 \mathrm{~mA})$ and the processes much more controlled.

To more accurately compare these tests with others in the literature, the same material (unoxidized Rene'N5) was tested in $1 \mathrm{~N}$ $\mathrm{H}_{2} \mathrm{SO}_{4}$ using a potentiostat and a standard saturated $\mathrm{Ag} / \mathrm{AgCl}$ reference electrode ( $\mathrm{CV}$ cell, where $E_{\mathrm{O}, \mathrm{Ag} / \mathrm{AgCl}}=+0.197 \mathrm{~V}$ on the hydrogen scale, Prof. N. Leventis, UMR [13]). The results are shown as the solid circles in Fig. 5. Now the transitions occur at $-0.4 \mathrm{~V}$ at the cathodic leg and $+1.0 \mathrm{~V}$ at the anodic leg. An additional comparison between this setup using an Au electrode (open squares) and ours using a Pt electrode (solid triangles) show good correspondence to within about $0.2 \mathrm{~V}$.
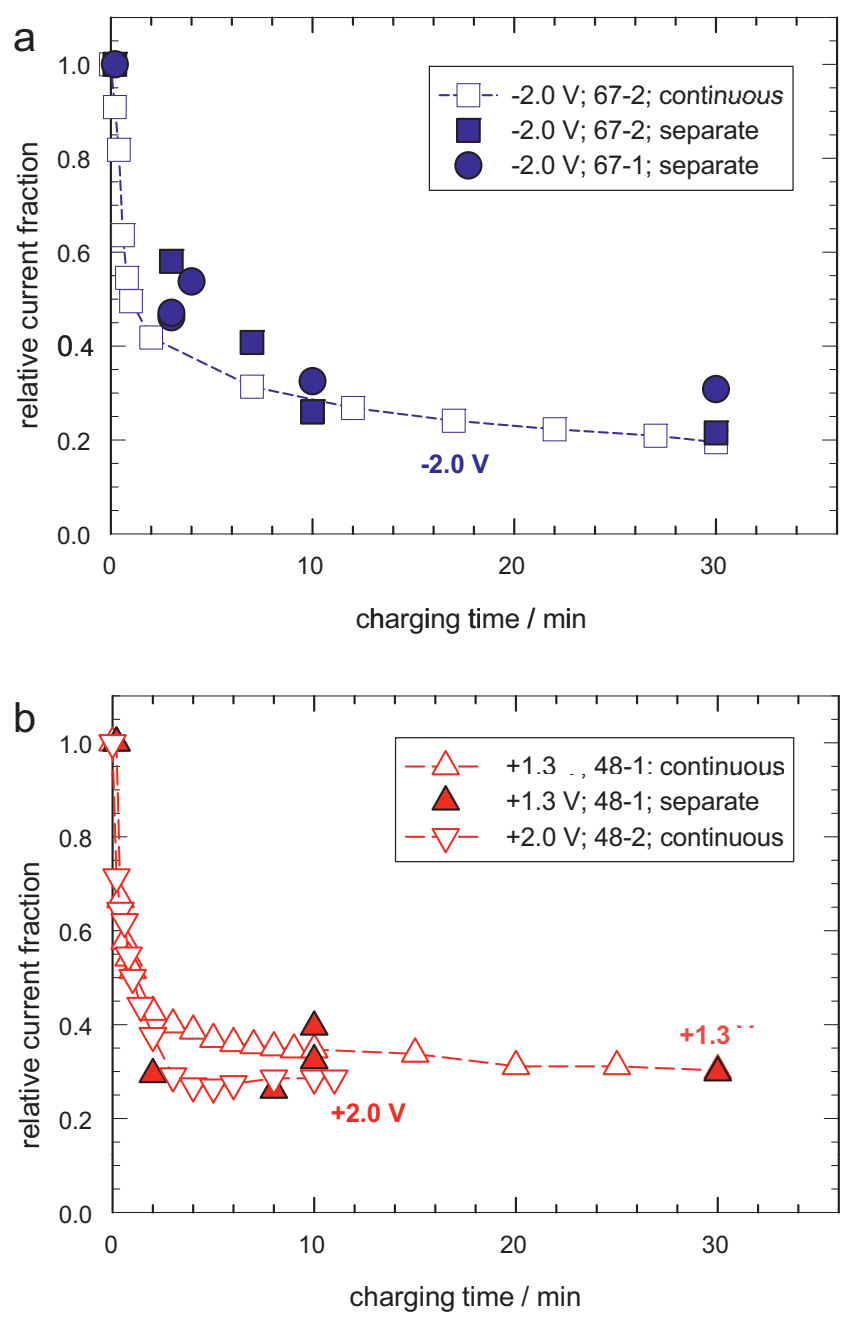

Fig. 3. Normalized current decay for intermittent polarizations of pre-oxidized Rene'N5. (a) cathodic: solid squares and circles and (b) anodic: solid triangles. 


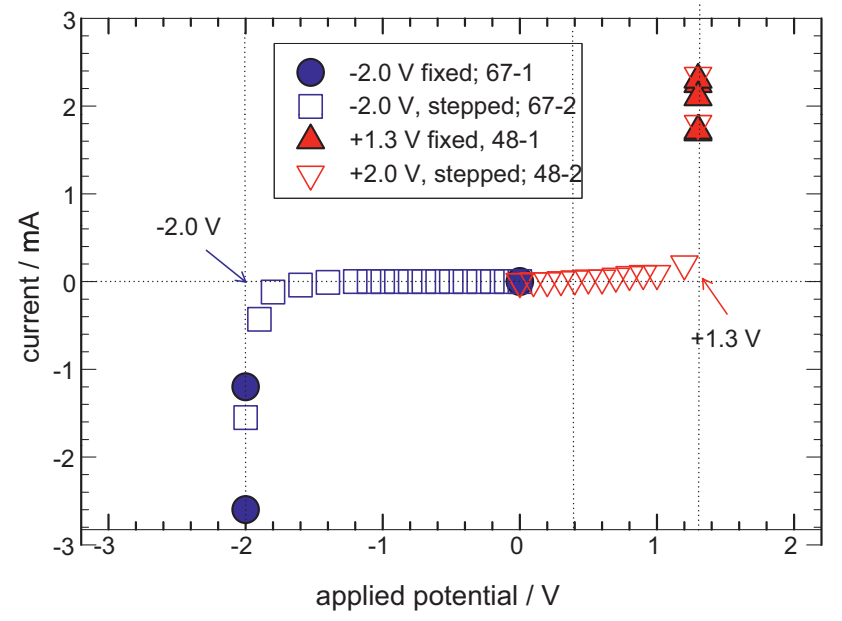

Fig. 4. Polarization voltammogram for pre-oxidized Rene'N5 showing cathodic knee at $-2.0 \mathrm{~V}$ and anodic knee at $+1.3 \mathrm{~V}$ (solid symbols: continuous exposures; open symbols: stepped voltage).

\subsection{Cathodic charging}

A simple electrolysis half-reaction is given below to describe cathodic (negative polarization) hydrogen charging:

$\mathrm{H}_{\mathrm{aq}}{ }^{+}+2 \mathrm{e}^{-}=\mathrm{H}_{\mathrm{ads}}$

from which no corrosion-related weight change is expected. However, the weight change behavior, summarized in Table 1 (along with pre-oxidation and immersion weights), suggests significant hydrogen effects. Sample 67-1 was very adherent in the oxidation test, gaining $0.9 \mathrm{mg} / \mathrm{cm}^{2}$ after 10001 -h cycles at $1150^{\circ} \mathrm{C}$. Then it lost only $0.07 \mathrm{mg} / \mathrm{cm}^{2}$ in the initial water immersion test. This behavior was typical of Y-doped Rene'N5 that had been hydrogen annealed [6,9]. Subsequent immersion in the electrolyte for an hour, without polarization, showed further weight loss of only $0.04 \mathrm{mg} / \mathrm{cm}^{2}$. However cathodic charging at $-2.0 \mathrm{~V}$ produced $2.7 \mathrm{mg} / \mathrm{cm}^{2}$ weight loss. This took place primarily in the first $20 \mathrm{~min}$, as shown in Fig. 6, followed by very little further weight loss. To put this quantity in perspective, the grown scales were near levels of $1 \mathrm{mg} / \mathrm{cm}^{2}$ mass gain of oxygen. This is equivalent to $2.1 \mathrm{mg} / \mathrm{cm}^{2}$ of alumina scale. Consequently, the $2.7 \mathrm{mg} / \mathrm{cm}^{2}$ weight loss would suggest total, massive spallation (and some spinel to account for the additional mass).

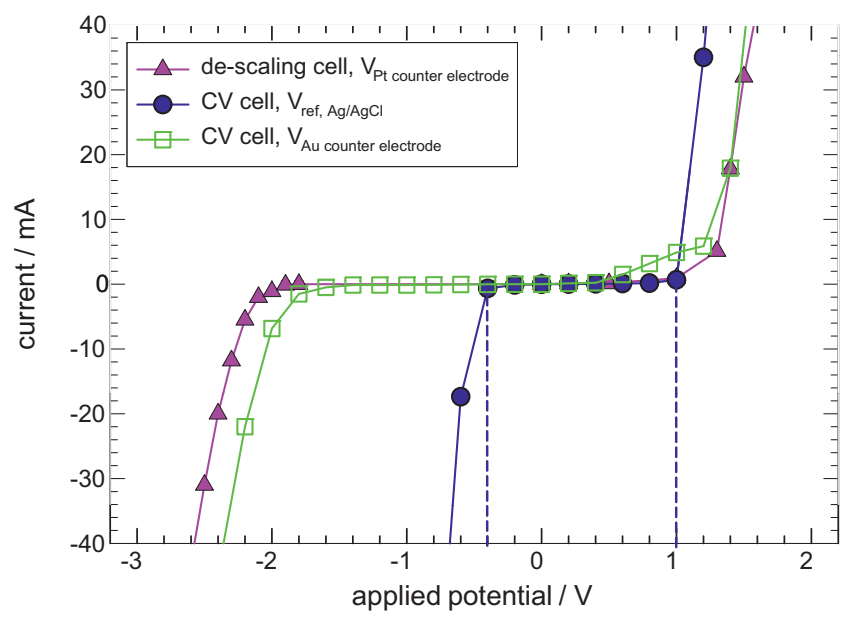

Fig. 5. Comparative voltammograms and polarization knees for bare Rene'N5 using $\mathrm{Pt}$ or Au counter-electrodes and saturated $\mathrm{Ag} / \mathrm{AgCl}$ standard reference electrode.

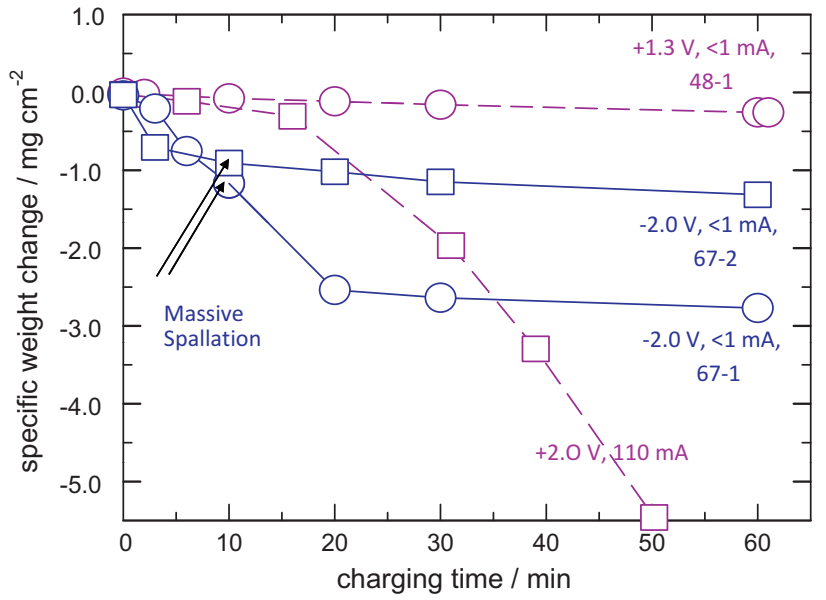

Fig. 6. Electrolytically induced weight losses for pre-oxidized Rene'N5: cathodic descaling and anodic dissolution.

The macrographs in Fig. 7 show that very little spalling to bare metal existed before polarization. But after the cathodic treatment, the scale was nearly completely stripped, leaving only small islands or particles of scale dispersed over the surface. These features are shown in more detail in the SEM micrographs in Fig. 8, presenting a SE/BSE pair. The SE image clearly reveals the oxide grain imprints in the metal, indicative of clean interfacial spallation. The corresponding BSE contains a number of cleaved dark particles, presumed to be entrapped $\alpha-\mathrm{Al}_{2} \mathrm{O}_{3}$ intrusions left from the interfacial scale delamination event. Fine Hf-rich submicron particles dispersed within the $\mathrm{Al}_{2} \mathrm{O}_{3}$ are presumed to be $\mathrm{HfO}_{2}$. In some areas the Hf-rich oxide was established as broader colonies [1]. Finally, bright Ta-rich particles, presumed to be $\mathrm{TaC}$ from known precipitates in this material, are seen here with the characteristic oxide grain imprints on their exposed surface. EDS substantiation of the above is shown in the spectra of Fig. 9 for (a) Ni-rich exposed oxide imprint metal area, (b) Ta-rich particle, (c) Al-rich oxide inclusion, and (d) Hf-rich stringers in the oxide.

Sample 67-2, oxidized in the as-received condition, was reasonably oxidation resistant but did lose $1.2 \mathrm{mg} / \mathrm{cm}^{2}$ in cycling and $0.1 \mathrm{mg} / \mathrm{cm}^{2}$ in subsequent water immersion. This behavior was typical of Y-doped Rene'N5 that had not been hydrogen annealed [6,9]. As such, there would be less intact alumina present for removal by the $-2.0 \mathrm{~V}$ cathodic treatment to follow. Thus the descaling behavior in Fig. 6, while again indicating substantial loss in the first $20 \mathrm{~min}$ of charging, then leveled off at about $1.3 \mathrm{mg} / \mathrm{cm}^{2}$ loss, or about $1 / 2$ that of the previous sample. Note that both $-2.0 \mathrm{~V}$ cathodic samples were charged at about $0.4 \mathrm{~mA}$ for most of the exposure. A sequence of the spalling behavior for 67-2 is shown in Fig. 10. Here, more numerous small spalled sites were present before charging $(0 \mathrm{~min})$. The progression of spalling features can be followed in greater detail by using the overlying grid to identify the same area in each photograph. After $10 \mathrm{~min}$, a majority of the scale was removed, with less, but measurable, new spallation occurring after $20 \mathrm{~min}$ and $60 \mathrm{~min}$. This decaying trend is consistent with decay of weight loss in Fig. 6.

\subsection{Anodic comparison}

The purpose for anodic exposures is simply to highlight the substantive difference in behavior compared to cathodic hydrogen charging and to reinforce the role that hydrogen plays in scale spallation. A simple reaction is given below that suggests anodic dissolution resulting from positive polarization:

$\mathrm{Ni}=\mathrm{Ni}^{2+}+2 \mathrm{e}^{-}$ 

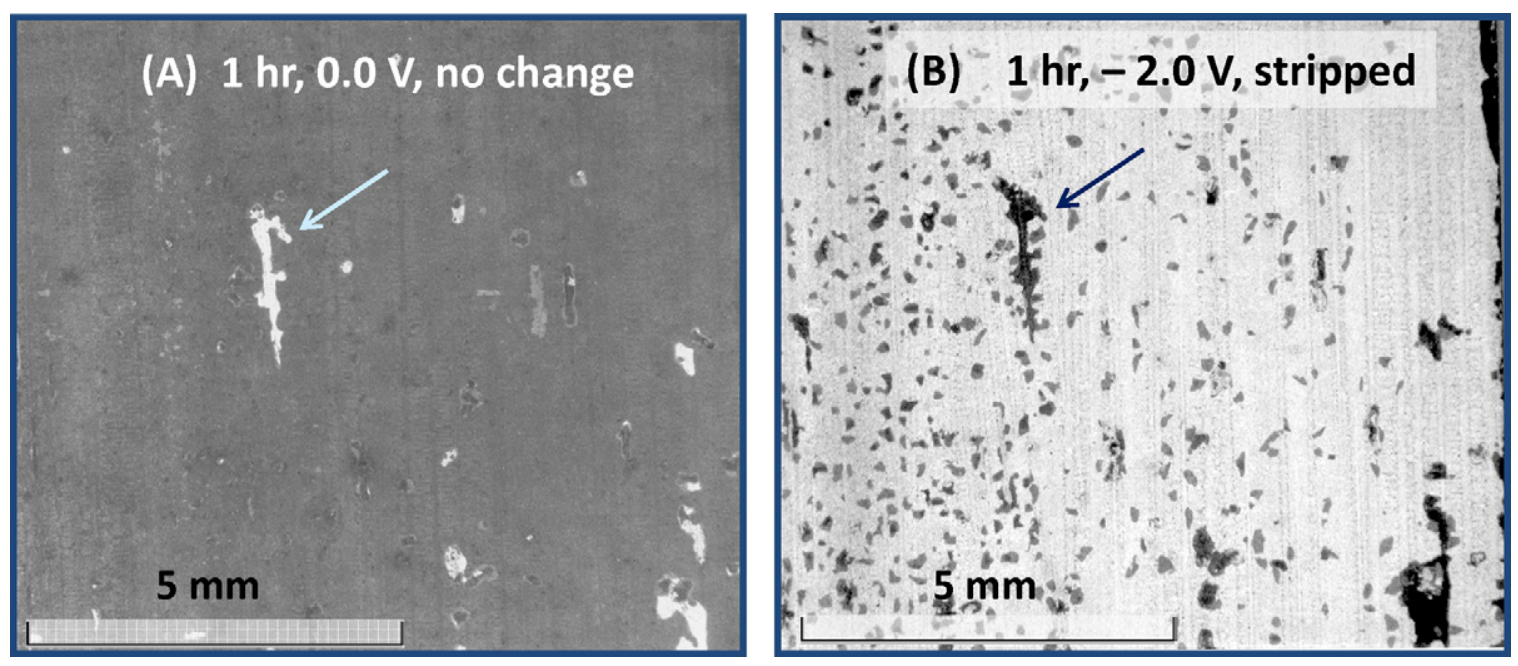

Fig. 7. Macrographs of surface structure produced by cathodic descaling of pre-oxidized Rene'N5 (sample $67-1$ ). (a) $60 \mathrm{~min}$ at $0.0 \mathrm{~V}$ and (b) $60 \mathrm{~min}$ at $-2.0 \mathrm{~V}$.

Accordingly, two similar samples were selected for exposure to anodic conditions. They had displayed similar behavior in the preceeding $1150^{\circ} \mathrm{C}$ cyclic oxidation, Table 1 . The first, sample, $48-1$, was held at the $+1.3 \mathrm{~V}$ anodic knee, producing a low $0.7 \mathrm{~mA}$ current. It lost weight gradually and quite linearly, consistent with dissolution effects, reaching $\sim 0.3 \mathrm{mg} / \mathrm{cm}^{2}$ after an hour. By comparison, a subsequent cathodic treatment at $-2.0 \mathrm{~V}$ for just 2 min produced a weight loss of $0.09 \mathrm{mg} / \mathrm{cm}^{2}$ due to scale spallation, i.e., at a rate nine times that of the overall anodic exposure.

For sample $48-2$, however, polarization at $+2.0 \mathrm{~V}$ resulted in a considerable anodic overvoltage producing $>100 \mathrm{~mA}$ current, a continuous high dissolution rate, and a weight loss over $5 \mathrm{mg} / \mathrm{cm}^{2}$, Fig. 6 and Table 1. The appearance of this sample showed basically an accentuated attack of the dendritic structure in the single crystal, as seen in the overview (A) and detail marked (B) in Fig. 11. Most remaining areas were intact $\mathrm{Al}_{2} \mathrm{O}_{3}$ scale, occasionally with a few adjacent areas that did actually spall at the metal interface. But it was clear that the majority of the weight loss was metal dissolution. The primary features were characterized by EDS spectra, as indicated in Fig. 11C for the scale and Fig. 11D for the $\mathrm{Ni}-\mathrm{Al}-\mathrm{Ta}(\mathrm{W})-\mathrm{Mo}-\mathrm{Cr}$ substrate. (Note that this sample produced a mass of black soot on the sample, but there is no source of carbon. It was presumably a by-product of metal dissolution or metal hydroxide formation, such that subsequent ultrasonic cleaning produced an additional $3 \mathrm{mg} / \mathrm{cm}^{2}$ weight loss.)

To further characterize the intermittent weight loss behavior during polarization, the average rate of weight loss over a given time segment was plotted against corresponding current for all the polarization tests, Fig. 12. Here the anodic and cathodic tests are shown as circles and squares, respectively. The anodic test of 481 at $+1.3 \mathrm{~V}$ (filled circles) shows very little variation of either the low weight-loss rate or current, as the test was maintained at the low current corresponding to the anodic knee in the polarization curve. For $48-2$, the applied potential was stepped at small increments up to $+2.0 \mathrm{~V}$, going well beyond the knee, giving a range of currents and causing a commensurate increase in weight-loss rate. This is to be expected for a cation dissolution process resulting from maintaining a positive potential on a metal conductor in an electrolyte.
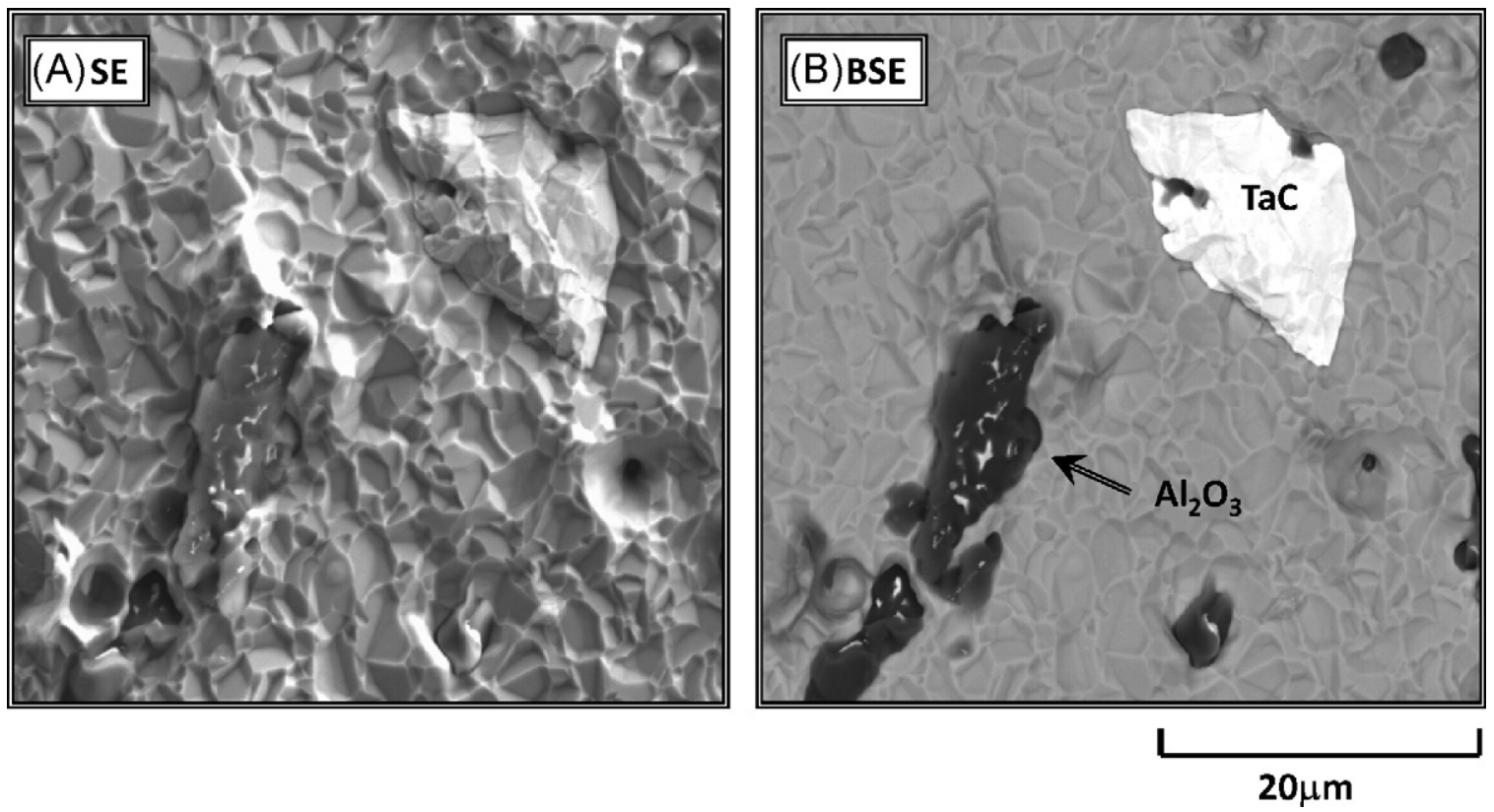

Fig. 8. SEM images (SE/BSE pair) of interfacial spalling produced by cathodic charging (sample 67-1). 


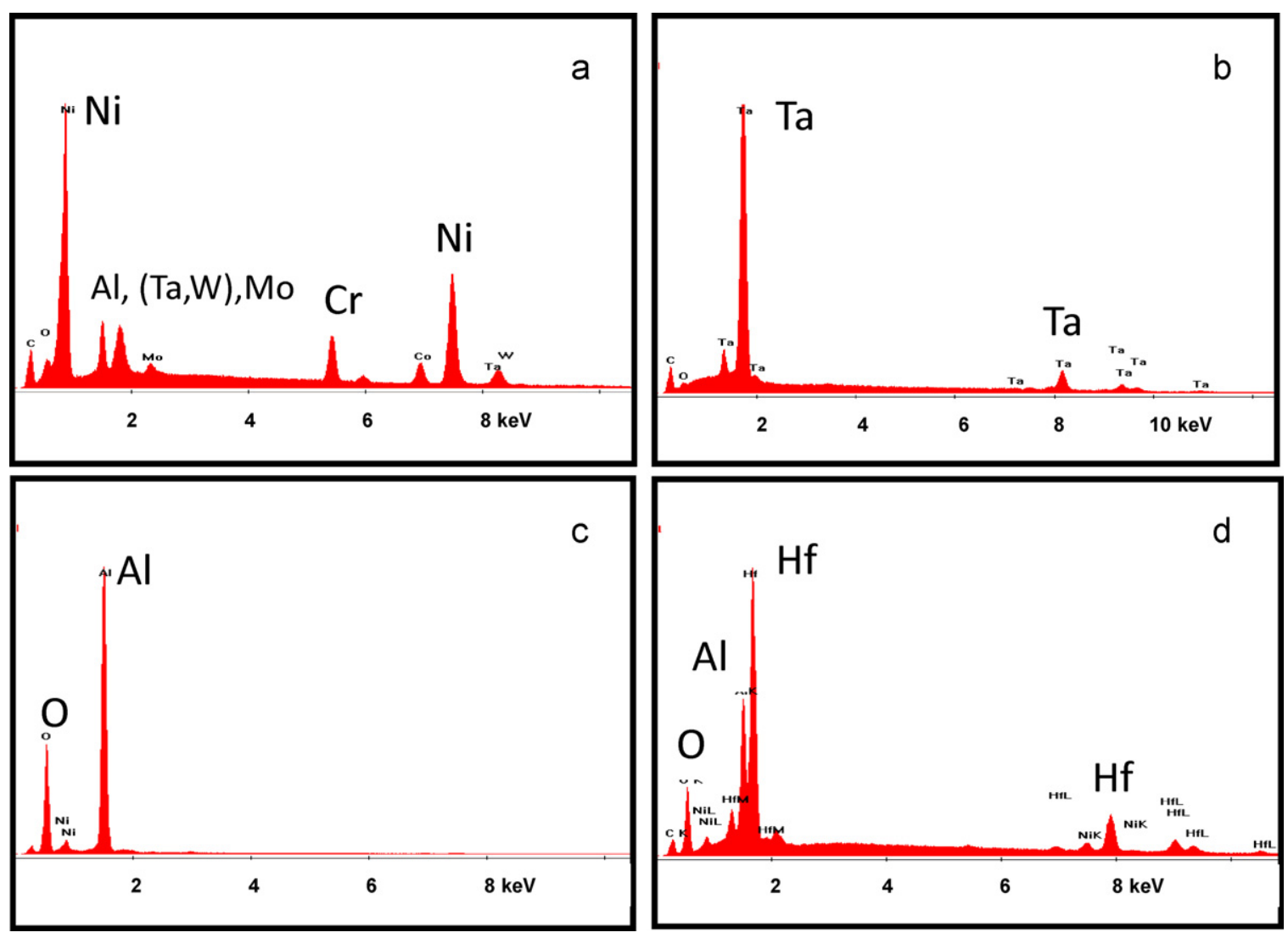

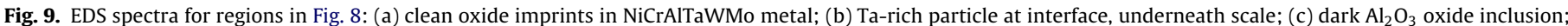
(d) bright $\mathrm{HfO}_{2}$ stringer in oxide particle (c).
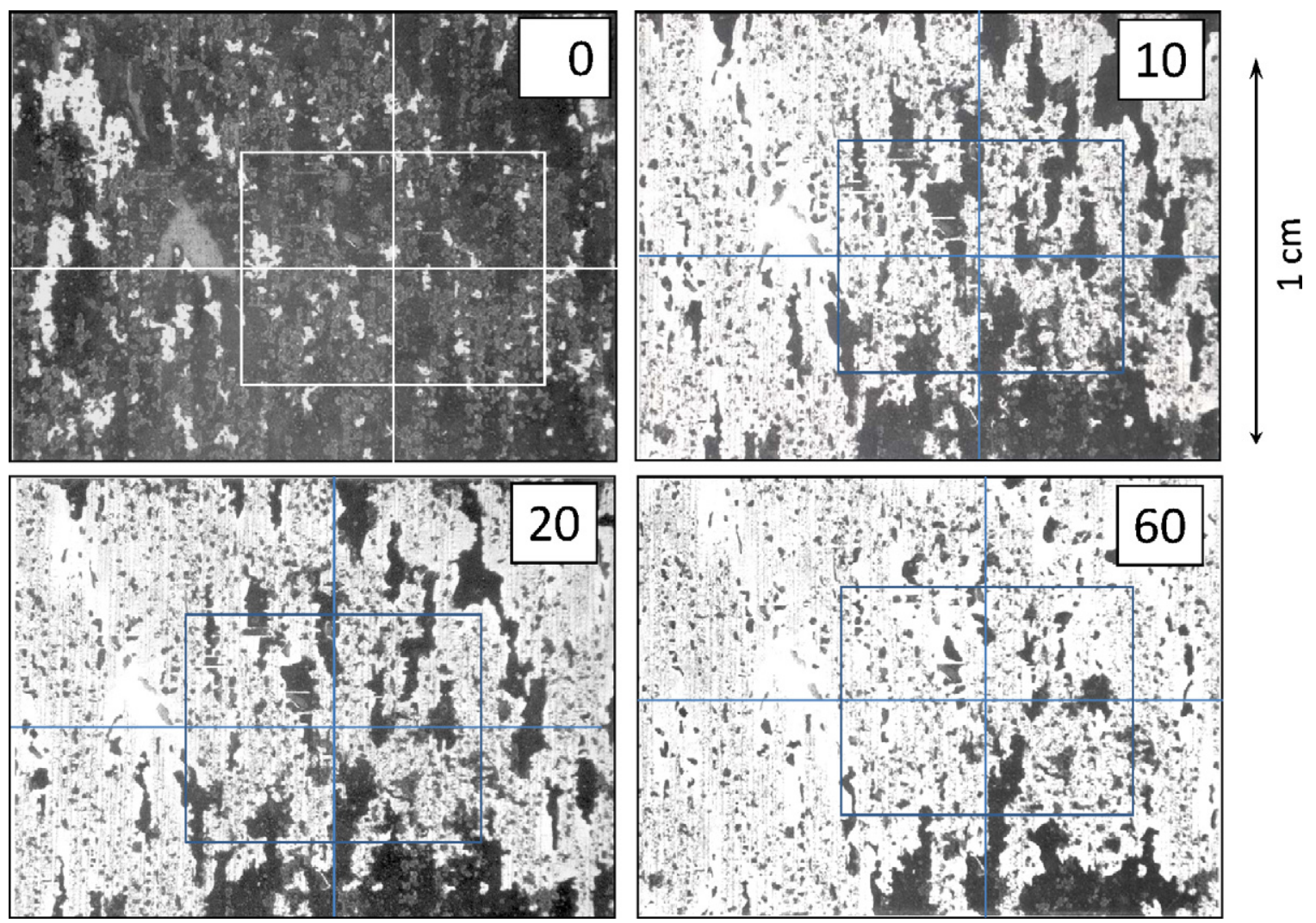

Fig. 10. Macrographs showing the progression of interfacial cathodic descaling with time $(0,10,20,60$ min, sample $67-2)$. 

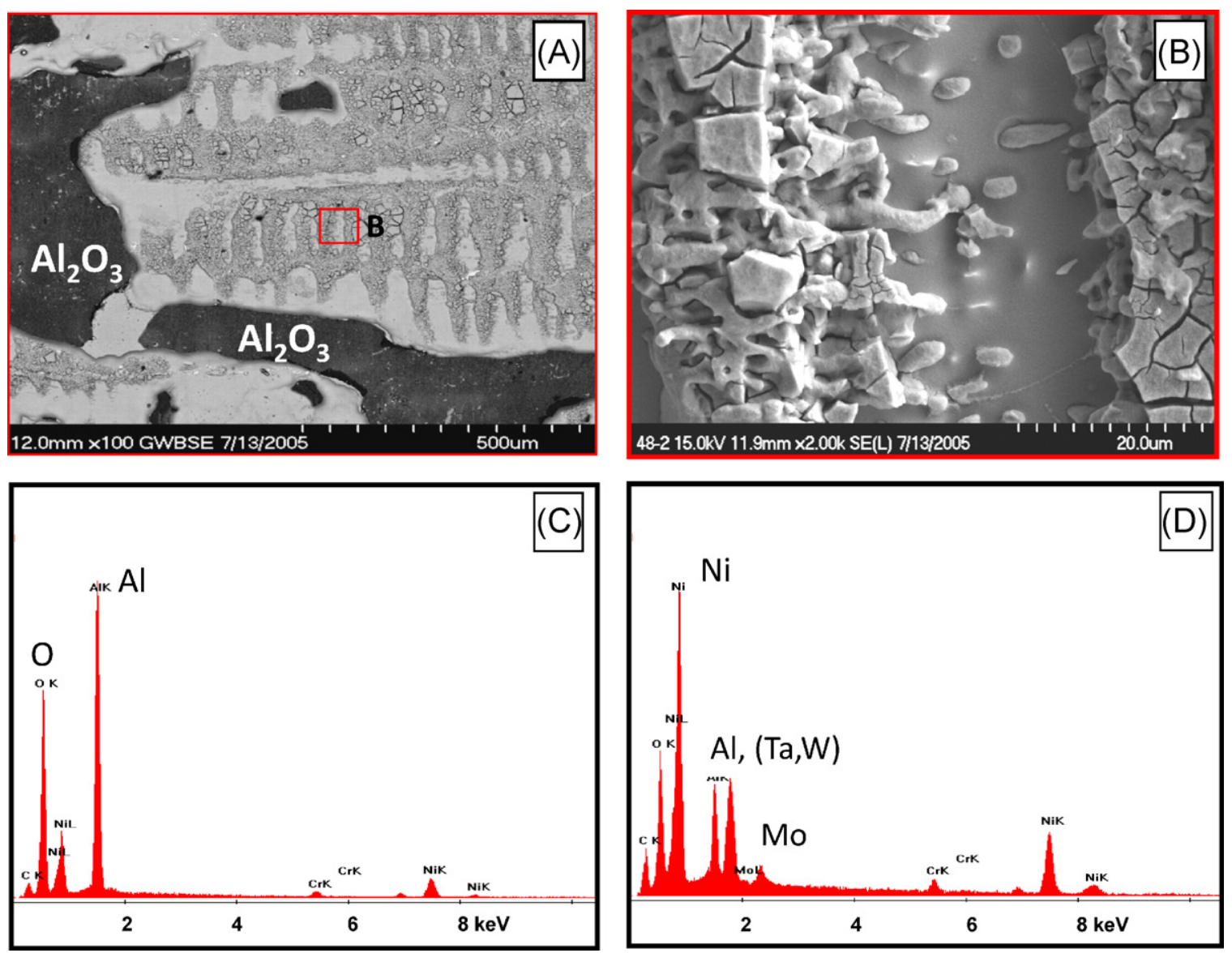

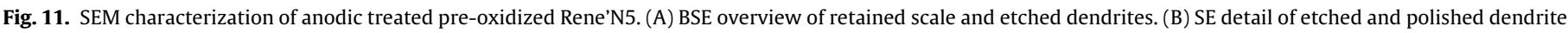
in metal single crystal. (C) EDS of retained $\mathrm{Al}_{2} \mathrm{O}_{3}$ scale in (A). (D) EDS of bare polished NiCrAlTaW dendrite.

In contrast, the weight-loss rate for the $-2.0 \mathrm{~V}$ cathodic polarizations shows a retrograde behavior, going through sharp maxima as the tests progress, all in the vicinity of the small $0.4-1.2 \mathrm{~mA}$ range of current. This is because scale delamination is finite and quickly completed for the small currents maintained throughout the test. The maxima simply correspond to the initial portion of the test, when the most scale is still present to spall, and are not uniquely dependent on various levels of current. (Higher polarization and currents would most likely produce higher rates of spalling, but

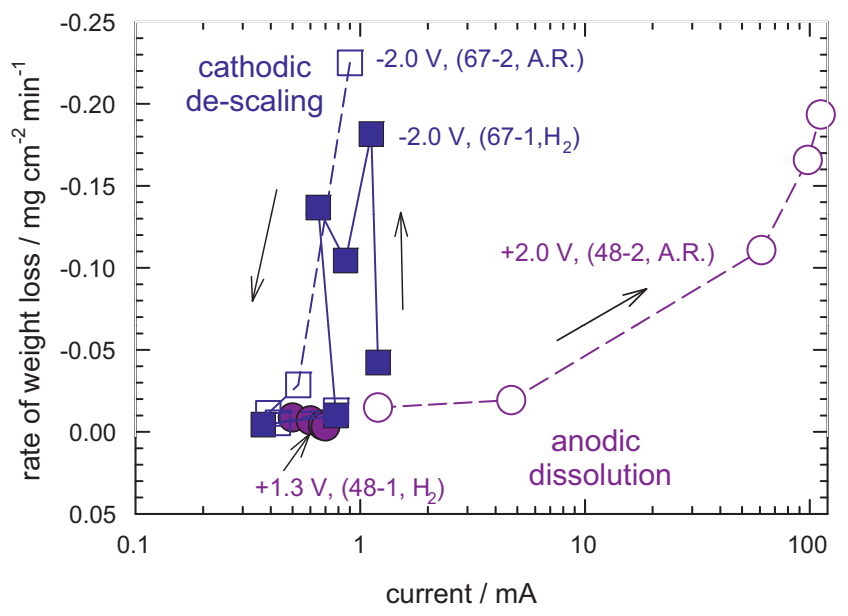

Fig. 12. Correlation of weight loss and electrolytic charging current for pre-oxidized Rene'N5. Arrows show trends with exposure time. only initially.) The significance of this figure is that polarization at low currents corresponding to the cathodic knee produce initial high weight-loss rates corresponding to descaling. In contrast, a low weight-loss rate occurs at the anodic knee, only increasing as the applied potential and current are increased, consistent with anodic dissolution. This characterization agrees essentially with the microstructural evidence presented above.

Since the basic tenet of this study is to show whether hydrogen charging can induce spallation, it is informative to show results for overcharging an unoxidized sample at higher applied potential and current. Here a polished, as-received undoped sample of Rene'N5 was subjected to potential extremes to further establish the polarization curve shown in Fig. 5. The anodic leg was taken to $+1.8 \mathrm{~V}$ and produced a weight loss of $4 \mathrm{mg} / \mathrm{cm}^{2}$. The cathodic leg was taken to $-3.0 \mathrm{~V}$ and exhibited a weight loss of $0.5 \mathrm{mg} / \mathrm{cm}^{2}$. More importantly, it exhibited surface features indicative of hydrogen induced embrittlement, swelling, and fracture, Fig. 13. Here cracking, bubbling and delamination are apparent in the bare metal (Fig. 13a). At the delaminated surface (Fig. 13b), it is seen that the network of cracks is at a high density on a micro-scale, spaced approximately every $10 \mu \mathrm{m}$. It finally reaches delineation and removal of material on the level of individual $\gamma^{\prime}-\mathrm{Ni}_{3} \mathrm{Al}$ particles (Fig. 13c), i.e., $<0.05 \mu \mathrm{m}$. The corresponding Ni-Al-Ta(W)-Mo-Cr EDS spectra (Fig. 13d) is consistent with that for a clean N5 alloy surface and comparable to the exposed metal spectra shown in Fig. 9a.

However it must be emphasized that this is not meant to imply that the more gentle hydrogen charging at $<1 \mathrm{~mA}$ and $-2.0 \mathrm{~V}$ or that naturally occurring MIDS itself is due to metallic embrittlement of the alloy. Rather it is proposed that primarily the interface is weakened by hydrogen, and spallation occurs without any decohesion 

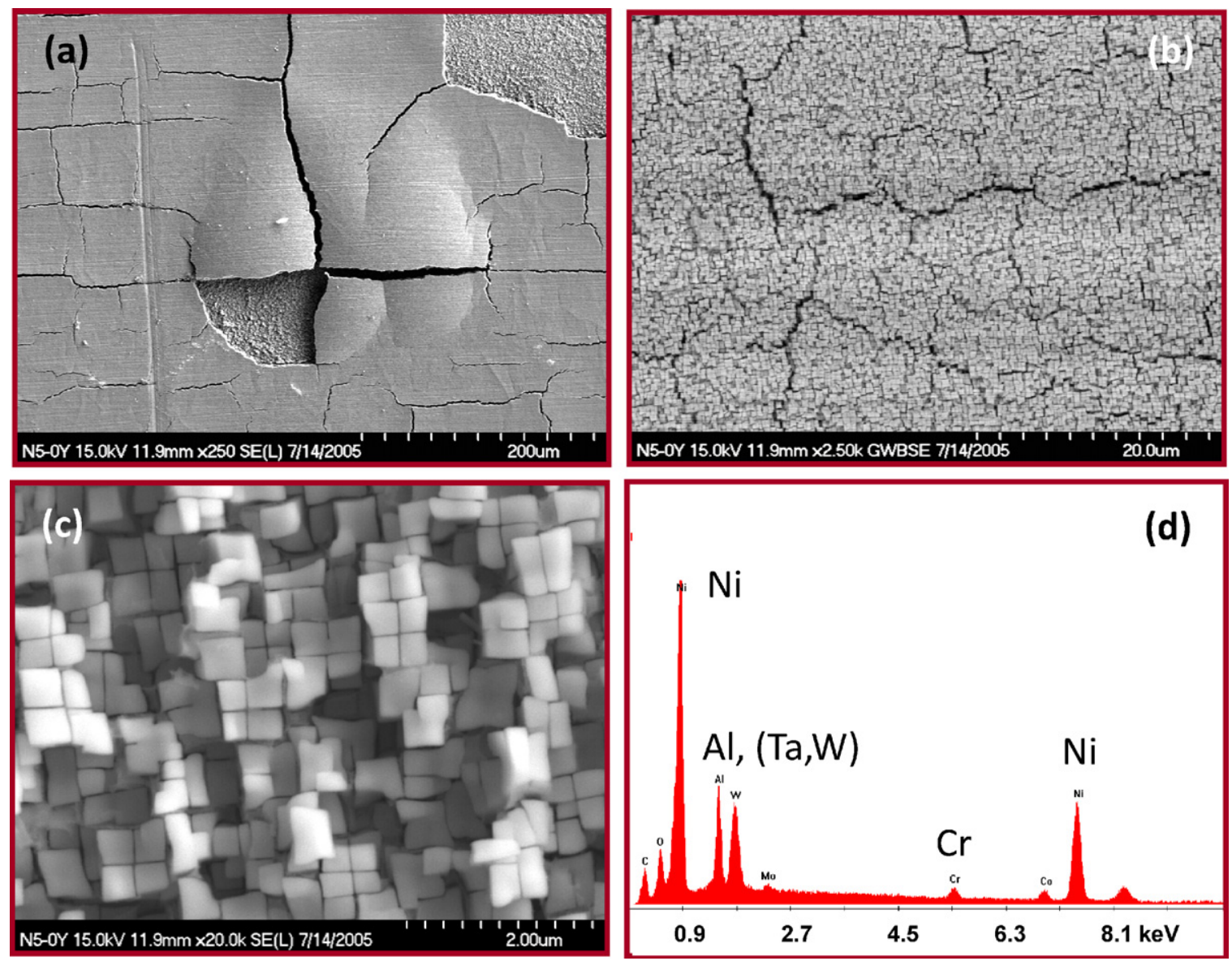

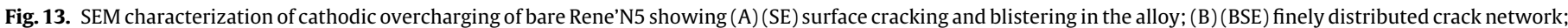
(C) (SE) individually etched $\gamma^{\prime}-\mathrm{Ni}_{3} \mathrm{Al}$ particles; (D) EDS of NiCrAlTaWMo alloy.

within the metal itself. This is evidenced by the clean spallation at the interface, and no damage to the underlying metal.

\subsection{The hydrogen factor in MIDS, cathodic embrittlement, and descaling}

The preceeding attempted to demonstrate that an external means of hydrogen introduction can cause delamination of essentially adherent $\mathrm{Al}_{2} \mathrm{O}_{3}$ scales. The process entails electrolytic cathodic charging used by numerous studies in demonstrating alloy susceptibility to hydrogen embrittlement. However to avoid complications from excessive gas evolution, the potential and current were carefully controlled to the point of just producing charge transfer with minimum chemical transitions. The results support the proposed hypothesis explaining moisture-induced delayed spallation (MIDS) of $\mathrm{Al}_{2} \mathrm{O}_{3}$ scales in terms of hydrogen embrittlement.

For general moisture effects that are observed after cooldown under ambient conditions, no applied potentials are needed. However the concept of local cells may apply, as is often employed to describe corrosion and film effects on crack growth (see schematics in Ref. [7] or [8]). Here $\mathrm{Al}^{3+}$ is anodically exsolved from the alloy by reacting with $\mathrm{H}_{2} \mathrm{O}$ and removing an $(\mathrm{OH})^{-}$group. This releases $\mathrm{H}^{+}$in solution to migrate away from the $\mathrm{Al}^{3+}$ sites, i.e., toward a cathodic interface as protected under an intact scale [1]. The mechanism may be lacking in proven details, but is consistent with typical observations of hydrogen embrittlement and intermittent crack growth in aqueous systems.
Other features in common with hydrogen embrittlement in metals are the preference for multiaxial tension and a negative, compounding effect with interfacial sulfur segregation. Biaxial tension exists in the metal at the interface, counteracting the biaxial compression in the scale, measured in mature alumina scales to be on the order of $4 \mathrm{GPa}$ [14]. These conditions tend to minimize the shear stress in the plane of oxidation, dislocation movement, and consequent stress relaxation. It has been proposed from quantum chemical cluster calculations that any interfacial sulfur will expand the bond distances across the interface [15]. Thus an expanded interface facilitates hydrogen diffusion, is further weakened by hydrogen, and can only accommodate strain by brittle fracture (or slip on planes inclined to the interface).

The interaction with sulfur is demonstrated by Jones in a hydrogen charging experiment of $\mathrm{Ni}$ tensile fracture rod specimens having various sulfur contents [12]. The results are reproduced in Fig. 14, where his curves (solid lines) have been fit to sigmoidal curves (dashed lines), and the data points have been omitted for clarity. The specifics of the fitted equations have been given in Ref. [8] and will be described below for Eq. (3). Hydrogen was introduced by cathodic charging in $1 \mathrm{~N} \mathrm{H}_{2} \mathrm{SO}_{4}$, at $-0.30,-0.56$, and $-0.72 \mathrm{~V}$ (as measured against a saturated calomel reference electrode, SCE). An in situ fracture apparatus allowed segregated sulfur to be measured at exposed grain boundaries by Auger spectroscopy. The results indicate increasing amounts of brittle intergranular fracture as the sulfur level (at fractions of a monolayer) and the cathodic hydrogen charging potential increase. The sigmoidal trends indicate limits close to zero for low sulfur, low hydrogen and close to $100 \%$ for high sulfur, high hydrogen conditions. This 


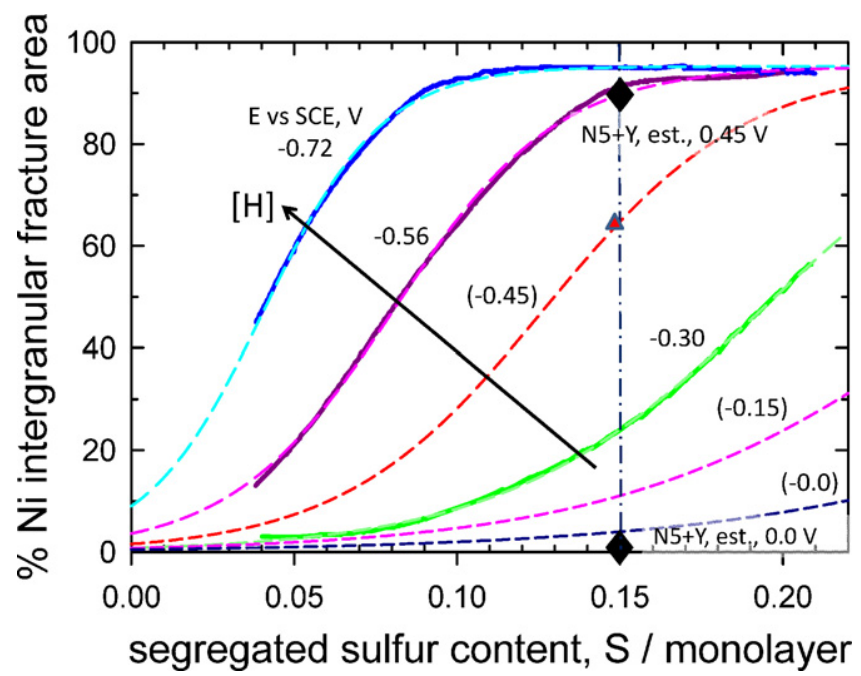

Fig. 14. Interfacial embrittlement vs interfacial sulfur content for hydrogen charged Ni tensile samples; cathodic (SCE) potential effects (from Jones [12]). Superimposed scale spallation (diamonds) for pre-oxidized Rene'N5, polarized to $-0.45 \mathrm{~V}$ or $0.0 \mathrm{~V}$ equivalent vs SCE. ( $V$ in parentheses, dashed estimated curves).

behavior results in a 'sweet zone' for manifesting hydrogen induced failure at intermediate sulfur levels, i.e, not too low to preclude brittle failure and not too high to allow brittle failure to occur even without hydrogen. In this region ( $\sim 0.10-0.50$ monolayer) one sees the maximum differential between low and high levels of hydrogen charging.

The concept of a 'sweet zone' for moisture-induced scale spallation has been introduced, presenting similar arguments derived from similar sigmoidal behavior [8]. Since interfacial sulfur was not often measured, we estimated from experience that this sensitive zone existed in the regime of 0.1-10 ppmw bulk sulfur content. In this range, some adhesion on cool down could be maintained, but subsequent moisture-induced spallation would be accentuated.

To further illustrate correlation of the cathodic descaling and $\mathrm{Ni}$ fracture tests, the potential of the descaling experiment was converted to that for an SCE reference electrode used in the Ni charging experiments. The results are shown in Table 2. Here $E_{0}$ for the saturated $\mathrm{Ag} / \mathrm{AgCl}$ reference electrode is $+0.197 \mathrm{~V}$, or $0.045 \mathrm{~V}$ less positive than that for SCE. Thus positive potentials will be converted to $0.045 \mathrm{~V}$ less and negative potentials will be converted to $0.045 \mathrm{~V}$ more differential for a SCE reference. Accordingly, the potential of the cathodic knee, where most of the hydrogen descaling was accomplished, converts from $-0.400 \mathrm{~V}$ (vs Ag/AgCl), from Fig. 5, to -0.445 vs SCE. Given the parameters used to fit the experimen- tal sigmoidal curves from Jones, we can interpolate and construct another at $-0.445 \mathrm{~V}$, as shown in Fig. 14 for the descaling experiments (dashed curve at midlevel). This positions the curve for $\mathrm{Ni}$ fracture at an applied potential equivalent to that used for descaling. To arrive at this curve, the Ni results were first fit according this sigmoidal equation:

$\% \mathrm{GBF}=\frac{a \times 100 \%}{\left\{1+\exp -\left(S-S_{0} / b\right)\right\}}$

where \%GBF represents the amount of brittle grain boundary fracture and the curve fit parameters are given in Table 3. $S$ is the measured interfacial sulfur level, $S_{0}$ is the sulfur level at the inflection of the sigmoidal curve, $a$ and $b$ are empirical fit parameters. At high values of $\left(S-S_{0}\right) / b$, the relation asymptotically approaches $a$ as a maximum; at low values the relation approaches zero. $S_{0}$ and $b$ are seen to decrease as the hydrogen charging potential goes to more negative values. However the maximum is seen to be close to $100 \%$ for all charging conditions. Also shown are extrapolated fit parameters for $(-0.0),(-0.15)$, and $(-0.445) \mathrm{V}$ vs SCE. These were then used to estimate additional curves at $0.30 \mathrm{~V}$ and $0.15 \mathrm{~V}$ (dashed) in Fig. 14.

We then proceed to estimate an amount of interfacial descaling and interfacial sulfur segregation to project Rene'N5 + Y on this template. Since the alloy retained sulfur ( $5.5 \mathrm{ppmw}$ ) during hydrogen annealing, the initial sulfur quantity ( $4.9 \mathrm{ppmw})$ was effectively tied up in Y-S complexes by the Y-dopant ( $80 \mathrm{ppmw}$ ) for sample 67-1. What might evolve with extensive oxidation is a rejection of sulfur at the interface as the scale grows, $\mathrm{Y}$ is incorporated in the scale, and the interface recesses. This exercise projected a maximum potential sulfur buildup of 0.15 monolayer for every $1 \mathrm{mg} / \mathrm{cm}^{2}$ of $\mathrm{Al}_{2} \mathrm{O}_{3}$ scale growth at a starting bulk sulfur content of $5 \mathrm{ppmw}$ [16]. Given the similarities for the present case (at $0.96 \mathrm{mg} / \mathrm{cm}^{2}$, Table 1 ), actually a model system for that recession exercise, the projection of 0.15 maximum sulfur segregation is a reasonable estimate.

Image analysis of macrographs for \% spallation area was performed for as-oxidized and after water immersion and produced, respectively $0.01 \%$ and $0.41 \%$ spallation area. Similarly, the image in Fig. 7a, for pre-oxidized Rene'N5 immersed in $\mathrm{H}_{2} \mathrm{SO}_{4}$ at $0.0 \mathrm{~V}$ for $1 \mathrm{~h}$, was measured to have $1.2 \%$ area spalled to bare metal. But interfacial spallation increased to $\sim 90 \%$, Fig. $7 \mathrm{~b}$, due to cathodic polarization (at about $-0.40 \mathrm{vs} \mathrm{Ag} / \mathrm{AgCl}$, equivalent to $-0.445 \mathrm{~V}$ vs SCE). These spall areas are shown on the Jones plot as diamonds, Fig. 14 . The $90 \%$ value at $-0.445 \mathrm{~V}$ thus corresponds to a predicted $\mathrm{Ni}$ intergranular fraction of $\sim 65 \%$, and the $1.2 \%$ value at $0.0 \mathrm{~V}$ corresponds to a predicted value of $\sim 4 \%$. This exercise illustrates a parallel trend in $\mathrm{Ni}$ embrittlement and $\mathrm{Al}_{2} \mathrm{O}_{3}$ interfacial spallation

Table 2

Equivalent $E_{0}$, grain boundary fracture and descaling 'knee' potentials for various reference electrodes.

\begin{tabular}{|c|c|c|c|c|c|c|c|}
\hline & & \multirow[t]{2}{*}{$E_{0}, \mathrm{~V}$} & \multicolumn{3}{|c|}{$E_{\mathrm{GBF}}$ (Jones) } & \multicolumn{2}{|c|}{$E_{\text {descaling }}$ (Leventis) } \\
\hline & & & 1 & 2 & 3 & Cathodic & Anodic \\
\hline Hydrogen & SHE & 0.000 & -0.478 & -0.318 & -0.058 & -0.303 & 1.197 \\
\hline sat'd AgCl & $\mathrm{AgCl}_{\mathrm{s}}$ & 0.197 & -0.675 & -0.515 & -0.255 & -0.400 & 1.000 \\
\hline sat'd calomel & SCE & 0.242 & -0.720 & -0.560 & -0.300 & -0.445 & 0.955 \\
\hline
\end{tabular}

Table 3

Parametric fits to Eq. (3) and extrapolated values for cathodic hydrogen grain boundary embrittlement of Ni (from Jones). $S$, monolayer of sulfur; $S_{0}$, inflection point.

\begin{tabular}{|c|c|c|c|c|c|c|}
\hline vs SCE & $0.00 \mathrm{~V}$ & $-0.15 \mathrm{~V}$ & $-0.30 \mathrm{~V}$ & $-0.445 \mathrm{~V}$ & $-0.56 \mathrm{~V}$ & $-0.72 \mathrm{~V}$ \\
\hline$a$ & 101.600 & 99.000 & 96.857 & 95.600 & 95.296 & 95.290 \\
\hline$b$ & 0.0700 & 0.0540 & 0.0406 & 0.0310 & 0.0250 & 0.0181 \\
\hline$S_{0}$ & 0.374 & 0.262 & 0.195 & 0.127 & 0.081 & 0.041 \\
\hline$R^{2}$ & N.A. & N.A. & 0.999 & N.A. & 0.999 & 0.997 \\
\hline
\end{tabular}




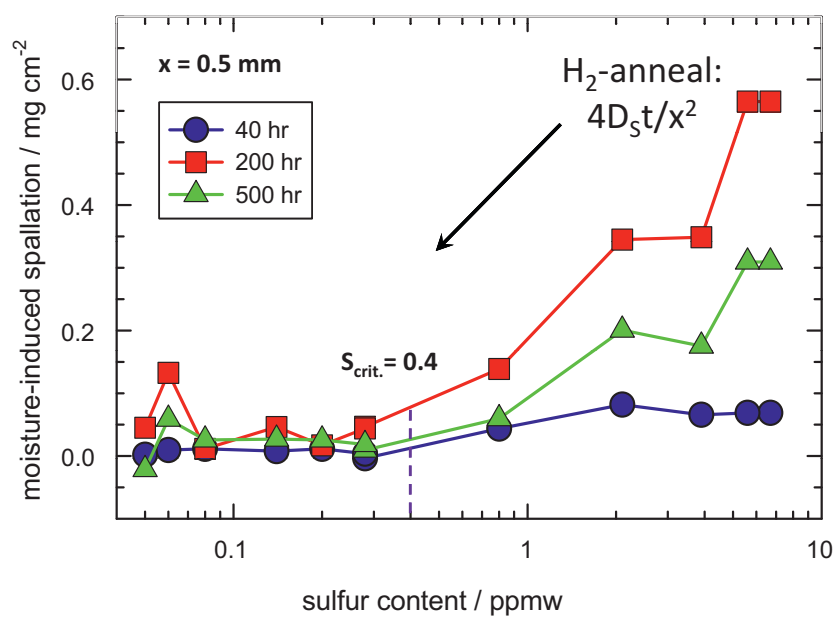

Fig. 15. Sulfur effect on moisture-induced delayed spallation for PWA 1480 preoxidized at $1100{ }^{\circ} \mathrm{C}$ for $40 \mathrm{~h}, 200 \mathrm{~h}$, and $500 \mathrm{~h}$.

produced by cathodic hydrogen charging. However this fractional spallation of $\mathrm{Al}_{2} \mathrm{O}_{3}$ scales may not follow the exact chemistry as uniaxial brittle fracture in $\mathrm{Ni}$.

In a similar vein, the MIDS observed for PWA 1480 can also be described within this $\mathrm{H}-\mathrm{S}$ context. Here the spallation produced by exposure to moisture after various amounts of $1100^{\circ} \mathrm{C} 1$-h thermal cycling is shown in Fig. 15 as a function of bulk sulfur content [17]. The sulfur content of individual samples was adjusted by varying the time and temperature of desulfurizing hydrogen anneals. The sulfur reduction was approximately controlled by the diffusion factor, $4 D_{S} t / x^{2}$, where $D_{\mathrm{S}}$ is the diffusivity of sulfur in $\mathrm{Ni}, t$ is the time of diffusion, and $x$ is the sample thickness. It can be seen that above about $0.4 \mathrm{ppmw} \mathrm{S}$, the MIDS phenomenon became increasingly apparent. This has been pointed out as a critical value for adhesion at this thickness, where the total amount of bulk sulfur accounts for about 1 monolayer equivalent [17].

The bulk sulfur can be then converted to an estimated surface segregation level according to the Langmuir-McClean isotherm, albeit for a free surface rather than interfaces. This relation (Eq. (3)) predicts a corresponding sulfur segregation level, $\theta_{S}$, as a function of bulk sulfur contents, $C_{S}$, and temperature. The segregation parameters were determined from the measurements of Miyahara et al. [18], as constructed in [19]:

$\frac{\theta}{1-\theta}=0.19 C_{\mathrm{S}} \exp \left\{\frac{137 \mathrm{~kJ}}{R T}\right\}$

where $\theta$ corresponds to the sulfur surface segregation level relative to an assumed maximum of 0.5 monolayer, and $C_{S}$ is the bulk level in atom fraction.

The MIDS data can now be presented (open symbols) as a function of estimated surface sulfur, Fig. 16 (right abscissa). Also shown are two measured XPS points (solid triangles) corresponding to an as-received and one hydrogen anneal treatment [20]. Superimposed is a scaled plot of the Ni intergranular embrittlement curve for cathodic hydrogen charging at $-0.56 \mathrm{~V}$ (left abscissa). The general similarity of the grain boundary fracture of Ni and MIDS for PWA 1480 at corresponding sulfur segregation levels is noteworthy. This supports the premise that similar additive effects of $\mathrm{H}$ and $\mathrm{S}$ occur for hydrogen embrittlement and moisture-induced scale spallation. This is again consistent with the assumption that hydrogen is a key factor responsible for the MIDS phenomena.

It is noted that the foremost $\mathrm{H}$ or $\mathrm{H}_{2} \mathrm{O}$ effects on interfacial weakening shown in Figs. 14 and 16 for Ni, PWA 1480, and Rene'N5 + Y occur at $0.05-0.20 \mathrm{ML}$ of segregated sulfur, gravitating toward less

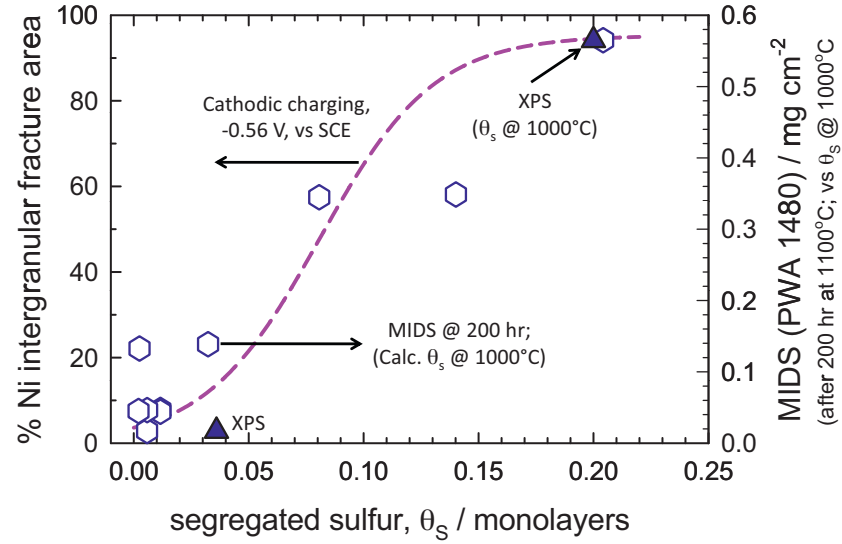

Fig. 16. Superposition of cathodic embrittlement of $\mathrm{Ni}$ (dashed) and MIDS data from $1100^{\circ} \mathrm{C}, 200 \mathrm{~h}$ oxidation of PWA 1480 (using estimated (open) and XPS measured (filled) sulfur surface segregation levels at $1000^{\circ} \mathrm{C}$ ).

sulfur at the higher charging voltage. This is compared to the extensive segregation studies of Hou, summarized in Ref. [21]. For $1000^{\circ} \mathrm{C}$ scales, $0.1-0.2 \mathrm{ML}$ of sulfur was measured for Ni40Al, 0.5 ML for Fe40Al, and 2.0 ML for Ni14Cr24Al and Fe18Cr10Al. The bulk sulfur content of these 4 alloys was $36 \mathrm{ppm}, 26 \mathrm{ppm}, 7 \mathrm{ppm}$, and 32 ppm S, respectively. A second FeCrAl alloy with 2 ppm bulk $\mathrm{S}$ exhibited $1 \mathrm{ML}$ of sulfur segregation. (The higher levels observed for $\mathrm{NiCrAl}$ and $\mathrm{FeCrAl}$ were associated with thick surface layers caused by $\mathrm{Cr}-\mathrm{C}-\mathrm{S}$ cosegregation effects.) In general, moisture and hydrogen effects are therefore projected to occur in undoped alloys with $0.01-10$ ppmw bulk $S$ and estimated sulfur segregation levels (0.01-0.2 ML) near those actually measured by the Auger studies (0.1-2.0 ML).

\subsection{Alternative MIDS mechanisms}

While this and other papers postulate that hydrogen is the key factor for MIDS, an alternative explanation is available. In Ref. [2] we point out that bulk alumina itself had been reported to be subject to moisture accelerated slow crack growth (static fatigue or stress corrosion) by Wiederhorn [22], later confirmed in numerous subsequent studies of moisture-assisted static and dynamic fatigue of alumina [23-28]. This phenomenon is based on moisture breaking strong $\mathrm{Al}-\mathrm{O}$ bonds in $\mathrm{Al}_{2} \mathrm{O}_{3}$ to form weak $\mathrm{Al}-(\mathrm{OH})$ bonds, presumably as some hydroxide species. It was applied to slow crack growth measurements for alumina scale buckling $[4,29,30]$ and directed toward alumina scale spallation by Meier and co-workers using cyclic oxidation in water vapor or subsequent room temperature water drop tests, e.g. [5,32,33].

However in a related acoustic emission study we argued that classic 'slow' crack growth, occurring at rates on the order of $10^{-6}-10^{-4} \mathrm{~m} / \mathrm{s}$ were seemingly incongruous with spallation rates that occurred instantaneously over many mm distances [6]. It was also argued here that sulfur at the interface results in a bond stretching and relaxed interface for moisture ingress, consistent with weakened interfaces being the most susceptible to MIDS. Other documentation of moisture-induced delayed, but 'fast,' fracture of the scale under a TBC (desktop spallation), taking 1-15 s at $\sim 10^{-2}-10^{-3} \mathrm{~m} / \mathrm{s}$, can be found in digital video recordings or captured frames [8,33-35]. Furthermore, subscale metal cracking has been observed and mentioned in support of a hydrogen induced mechanism [35].

Additionally, moisture enhanced slow crack growth and corrosion fatigue has been observed in numerous fracture toughness studies of alumina-metal sandwiches by Evans et al. [36-41]. Here 
the interface toughness is reduced by testing in ambient humidity compared to dry atmospheres for $\mathrm{Au}, \mathrm{Ni}$, and $\mathrm{NiCr}$. Since no moisture-induced oxidation reaction would be expected for $\mathrm{Au}$ sandwiches, these experiments may preclude hydrogen generation and tend to favor the corrosion fatigue model over hydrogen embrittlement. However it has been argued [39] that ubiquitous carbon impurities initially enabled moisture-induced degradation for Au couples [37]. Accordingly, some form of $\mathrm{C}-\mathrm{H}_{2} \mathrm{O}$ interface 'oxidation' reaction is possible, again along with hydrogen generation as a by-product. Furthermore, the possibility of a special interface gold 'oxide state' was discussed [39], which again would be accompanied by the release of hydrogen during the decomposition of $\mathrm{H}_{2} \mathrm{O}$, analogous to the path intimated by Eq. (2).

In the end, moisture is claimed to reduce the interfacial toughness, one way or the other. Currently there is no independent verification that $\mathrm{Al}-(\mathrm{OH})$ bonds are formed or that interfacial $\mathrm{H}$ is not formed in the case of MIDS. But it is known from the present study that hydrogen can independently degrade the interface. Still, neither chemical route can be conclusively proven or disproven for naturally occurring MIDS with the evidence at hand. It is especially paradoxical to point out that both mechanisms entail the formation of $\mathrm{Al}(\mathrm{OH})_{3}$ (in Eqs. (1) and (2)), making it accordingly difficult to isolate factors and perform critical experiments. To this end, exposures to liquid water free hydrocarbons may provide some insight. Recently we have observed reduced, but measurable spallation for organic solvents, such that water > ethanol > acetone. It may be argued that 190 proof ethanol still contained 5\% water or that acetone contains both $\mathrm{H}$ and $\mathrm{O}$ atoms and the potential for $\mathrm{Al}(\mathrm{OH})_{3}$ formation still exists. Thus, oxygen-free solvents, such as toluene or hexane, may provide a more definitive conclusion in terms of possible reaction paths.

\subsection{Oxidation in water vapor}

While outside the scope of the present work, it is acknowledged that realistic exposures would entail high temperature exposure to moisture as well, such as in combustion products in heat engines. There are many studies of water vapor effects on high temperature oxidation that report any number of effects, or none, depending on alloy, temperature, and moisture content. Effects on growth rate, scale phases, internal oxidation, molecular transport, hydrogen injection, hydroxide formation, etc. have been all reported and cannot be adequately dealt with here. For example, hydrogen generation during low temperature oxidation of steels are provided in Refs. [42,43] and during high temperature oxidation of $0-9 \mathrm{Cr}$ steels [44,45], NiCoCrAlY [46] and Fe-20Cr and FeNiCrAl [47]. Significant moisture-enhanced intermediate temperature transient oxidation of alumina-forming alloys is also described in Refs. $[5,31,32,48,49]$.

While important in their own scope, these high temperature effects do not necessarily apply directly to the MIDS phenomenon discussed here, i.e., for a scale grown in ambient (dry) air, then exposed to moisture after cooling. It is noted that for similar second generation single crystal alloys, higher temperature cyclic oxidation in water vapor generally did not affect the weight change response, nor presumably any growth process, for low sulfur alloys or Pt-modified aluminide coatings that form adherent alumina scales $[5,29,30]$. Only for $>1$ ppmw sulfur alloys or conventional aluminides, known to already exhibit some cyclic cracking and spalling of the scales in dry air, did water vapor exacerbate the spalling problem, as expected. This reinforces the concept that moisture affects alumina scale adhesion primarily by access to an exposed scale-metal interface at room temperature. This occurs without the need for any $\mathrm{H}_{2} \mathrm{O}$ or reaction product penetration through an intact growing scale at high temperature.

\section{Conclusions}

This study shows that conventional cathodic hydrogen charging produces massive, discontinuous interfacial scale spallation of otherwise adherent $\mathrm{Al}_{2} \mathrm{O}_{3}$ scales on pre-oxidized Rene'N5+Y superalloy samples. This occurs at minimal $<1 \mathrm{~mA}$ levels of cathodic current, while correspondingly low levels of anodic current produce slow, linear metal dissolution and minimal mass loss. The corresponding cathodic and anodic potentials were $-2.0 \mathrm{~V}$ and $+1.3 \mathrm{~V}$ using a Pt working electrode. These operational 'knees' in the voltammogram polarization curve, were subsequently measured to be $-0.40 \mathrm{~V}$ and $+1.0 \mathrm{~V}$ when measured against a saturated $\mathrm{Ag} / \mathrm{AgCl}$ reference electrode. Higher cathodic potential and currents can indeed embrittle, blister, and crack the superalloy by excessive hydrogen charging. However none of this was observed in the simple descaling exposure at lower cathodic potentials.

This study allowed comparison to the hydrogen charged $\mathrm{Ni}$ embrittlement work of Jones, where brittle fracture increased with cathodic potentials, as measured against SCE reference electrodes. The amount of scale delamination $(\approx 90 \%$ surface area) was found to exceed the interpolated level of Ni grain boundary embrittlement $(\approx 65 \%$ fracture area) for equivalent potentials. Shorter hydrogen diffusion distances for small scale segments compared to a bulk tensile sample may play a role here. Differences in brittle fracture area may also result from the stress state of uniaxial tension for $\mathrm{Ni}$ embrittlement compared to biaxial compressive failure of the hydrogen charged scales.

Another superalloy, PWA 1480, plotted against estimated and measured sulfur segregation levels, also displays MIDS behavior parallel to the sigmoidal cathodic Ni embrittlement. Both comparisons illustrate the similarities between cathodic hydrogen charging embrittlement of $\mathrm{Ni}$ and scale spallation for superalloys, whether the latter was produced by cathodic hydrogen charging or simply by exposure to moisture.

In total, the present study draws attention to the possible hydrogen factor in explaining the mechanism of moisture-induced scale spallation. This analysis highlights a key attribute common to moisture-induced spallation, namely that it occurs primarily for at-risk (sulfur-weakened), highly stressed interfaces. However, the converse, i.e., whether spallation is prevented by the absence of moisture (i.e., hydrogen), even at high sulfur contents, remains an intriguing concept.

The literature for high temperature oxidation of aluminaforming alloys in moist environments reveals a potential for enhanced transient oxidation and growth rates, internal oxidation, hydrogen generation, and increased spallation. However, increased spallation, the subject of this work, is believed to be primarily an ambient room temperature effect, i.e., it has been shown that spallation can occur just by exposure to moisture at room temperature. It does not necessarily rely on having moisture in the high temperature oxidation environment.

The literature for corrosion fatigue in alumina systems is reasonably consistent with delayed failure of alumina scales. There are sometimes wide divergences in 'slow crack growth' velocities of these studies and the rapid failure often observed for moistureinduced scale failure. The present hydrogen charging experiment is consistent with a hydrogen-based moisture phenomenon. The energetics of the associated chemical interfacial reactions appear to favor the hydrogen route over corrosion fatigue by three orders of magnitude.

\section{Acknowledgements}

Electrochemical measurements and helpful discussions of Prof. $\mathrm{N}$. Leventis are gratefully acknowledged, as are consultations with Dr. R. Jones, Dr. N. Jacobson, and Prof. R. Rapp, and the SEM/EDS 
work of Dr. A. Garg. Rene'N5 + Y samples were kindly provided by Dr. Jon Schaeffer and Wendy Murphy of General Electric Corporation.

\section{References}

[1] J.L. Smialek, Moisture-Induced Delayed Spallation and Interfacial Hydrogen Embrittlement of Alumina Scales, NASA TM 2005-214030, December 2005, p. 1. http://gltrs.grc.nasa.gov/reports/2005/TM-2005-214030.pdf.

[2] J.L. Smialek, Adherent $\mathrm{Al}_{2} \mathrm{O}_{3}$ scales formed on undoped $\mathrm{NiCrAl}$ alloys, in: M.A. Dayananda, S.J. Rothman, W.E. King (Eds.), Presented at the N.L. Peterson Mem. Symp. Proc. on Oxidation of Metals and Associated Mass Transport, Orlando, FL, October, 1986, TMS Proceedings, Warrendale, PA, 1987, p. 297.

[3] J.L. Smialek, Adherent scales produced on uncoated superalloys: desulfurized Rene'142 and Rene'N5, Presented at The David L. Douglass Symposium on High Temperature Corrosion, Extended Abstracts, The Electrochemical Society, Paper No. 525, 1994, p. 833.

[4] V. Sergo, D.R. Clarke, J. Am. Ceram. Soc. 81 (1998) 142.

[5] R. Janakiraman, G.H. Meier, F.S. Pettit, Metall. Mater. Trans. 30A (1999) 2905

[6] J.L. Smialek, G.N. Morscher, Mater. Sci. Eng. A 332 (2002) 11.

[7] J.L. Smialek, JOM 1 (2006) 29.

[8] J.L. Smialek, Moisture-Induced Alumina Scale Spallation: The Hydrogen Factor, NASA/TM-2010-216260, April, 2010, p. 1. http://gltrs.grc.nasa.gov/ reports/2010/TM-2010-216260.pdf.

[9] J.L. Smialek, B.A. Pint, Mater. Sci. Forum 369-372 (2001) 459-466. http://gltrs.grc.nasa.gov/reports/2000/TM-2000-210362.pdf.

[10] A.K. Kuruvilla, N.S. Stoloff, Scr. Metall. 19 (1985) 83.

[11] N.S. Stoloff, D.J. Duquette, JOM 45 (1993) 30

[12] R.H. Jones, Hydrogen and impurity-induced intergranular crack growth, in: N.R. Moody, A.W. Thompson (Eds.), Hydrogen Effects on Material Behavior, 817-843, TMS, Warrendale, PA, 1990.

[13] N. Leventis, U. Missouri-Rolla, unpublished research, 2005.

[14] R.J. Christensen, V.K. Tolpygo, D.R. Clarke, Acta Mater. 45 (1) (1997) 761.

[15] S.Y. Hong, A.B. Anderson, J.L. Smialek, Surf. Sci. 230 (1990) 174

[16] J.L. Smialek, Scr. Mater. 45 (2001) 1327.

[17] J.L. Smialek, Enigmatic moisture effects on $\mathrm{Al}_{2} \mathrm{O}_{3}$ scale and TBC adhesion, in: Pierre Steinmetz, Ian Wright (Eds), High Temperature Corrosion and Protection-7, Mater. Sci. Forum 595-598 (2008) 191. http://gltrs.grc. nasa.gov/reports/2008/TM-2008-215206.pdf.

[18] T. Miyahara, K. Stolt, D.A. Reed, H.K. Birnbaum, Scr. Met. 19 (1985) 117.
[19] J.L. Smialek, D.T. Jayne, J.C. Schaeffer, W.H. Murphy, Thin Solid Films 253 (1994) 285.

[20] D.T. Jayne, J.L. Smialek:, A sulfur segregation study of PWA 1480, NiCrAl, and NiAl alloys, in: S.B. Newcomb, M.J. Bennett (Eds.), Microscopy of Oxidation II, Institute of Metals, 1993, p. 183.

[21] P.Y. Hou, Annu. Rev. Mater. Res. 38 (2008) 275.

[22] S.M. Wiederhorn, Int. J. Fract. Mech. 4 (1968) 171.

[23] D.M. Kotchick, E. Tressler, J. Mater. Sci. 10 (1975) 608

[24] J.E. Ritter, J.N. Humenik, J. Mater. Sci. 14 (1979) 626

[25] M. Reece, F. Guiu, J. Am. Ceram. Soc. 74 (1991) 148.

[26] M. Nagabhooshanam, V.R. Dunke, J. Mater. Sci. 27 (1992) 2377.

[27] S. Barinov, N.V. Ivanov, S.V. Orlov, V.J. Shevchenko, J. Eur. Ceram. Soc. (1998) 2057.

[28] J.J. Kruzic, R.M. Cannon, R.O. Ritchie, Am. Ceram. Soc. 88 (2005) 2236.

[29] J.S. Wang, A.G. Evans, Acta Mater. 46 (1998) 4993.

[30] V.K. Tolpygo, D.R. Clarke, Mater. Sci. Eng. A278 (2000) 142.

[31] M.C. Maris-Sida, G.H. Meier, F.S. Pettit, Metall. Trans. 34A (2003) 2609.

[32] K. Onal (Hance), M.C. Maris-Sida, G.H. Meier, F.S. Pettit, Microscopy of Oxidation, 5, Materials at High Temperatures, 2003, p. 81.

[33] J.L. Smialek, D. Zhu, M.D. Cuy, Scr. Mater. 59 (2008) 67.

[34] M. Rudolphi, D. Renusch, M. Schütze, Scr. Mater. 59 (2008) 255.

[35] V. Déneux, Y. Cadoret, S. Hervier, D. Monceau, Oxid. Met. 73 (2010) 83, doi:10.1007/s11085-009-9170-1.

[36] I.E. Reimanis, B.J. Dalgleish, M. Brahy, M. Rühle, A.G. Evans, Acta Met. Mater. 38 (1990) 2645

[37] I.E. Reimanis, B.J. Dalgleish, A.G. Evans, Acta Met. Mater. 39 (1991) 3133.

[38] X. Mao, A.G. Evans, Acta Mater. 45 (1997) 4263.

[39] D.M. Lipkin, D.R. Clarke, A.G. Evans, Acta Mater. 46 (1998) 4835

[40] F.G. Gaudette, S. Suresh, A.G. Evans, G. Dehm, M. Rühle, Acta Met. 45 (1997) 3503.

[41] F.G. Gaudette, S. Suresh, A.G. Evans, Metall. Mater. Trans. 31A (2000) 1977.

[42] E. Akiyama, K. Matsukado, M. Wang, K. Tsuzaki, Corros. Sci. 52 (2010) 2758.

[43] S. Li, Z. Zhang, E. Akiyama, K. Tsuzaki, B. Zhang, Corros. Sci. 52 (2010) 1660.

[44] L. Tomlinson, N.J. Cory, Corros. Sci. 29 (1989) 939.

[45] J.P. Abellán, Y. Olszewski, G.H. Meier, L. Singheiser, W.J. Quakakkers, Int. J. Mater. Res. 101 (2010) 287.

[46] S. Subanovic, D. Naumenko, M. Kamruddin, G. Meier, L. Singheiser, W.J. Quadakkers, Corros. Sci. 51 (2009) 446.

[47] M.P. Brady, M. Fayek, J.R. Keiser, H.M. Meyer III, K.L. More, L.M. Anovitz, D.J. Wesolowski, D.R. Kole, ORNL, unpublished research, 2010.

[48] C. Zhou, H. Xu, S. Gong, Oxid. Met. 62 (2004) 195.

[49] M.P. Brady, Y. Yamamoto, M.L. Santella, L.R. Walker, Oxid. Met. 72 (2009) 311. 